\title{
Repeated broad ligament hematomas managed by uterine artery embolization: time to execute
}

\author{
Subrat Panda ${ }^{1}$, Nalini Sharma ${ }^{1 *}$, Pranjal Phukan ${ }^{2}$
}

${ }^{1}$ Department of Obstetrics and Gynecology, NEIGRIHMS, Shillong, Meghalaya, India
${ }^{2}$ Department of Radiology, NEIGRIHMS, Shillong, Meghalaya, India

Received: 29 May 2019

Accepted: 09 July 2019

\section{*Correspondence:}

Dr. Nalini Sharma,

E-mail: nalinisharma100@rediffmail.com

Copyright: () the author(s), publisher and licensee Medip Academy. This is an open-access article distributed under the terms of the Creative Commons Attribution Non-Commercial License, which permits unrestricted non-commercial use, distribution, and reproduction in any medium, provided the original work is properly cited.

\begin{abstract}
Selective arterial embolization (SAE) of the uterine arteries is an alternative to surgery when medical management fails in cases of intractable posrtpartum haemorrhage. It is highly efficacious with low complication rate. Here we report a case of repeated broad ligament haematoma managed by selective uterine artery embolization. Present case 28year old P4L4 was referred from a district hospital as post LSCS case with broad ligament haematoma. Patients general condition was very poor at the time of admission. She underwent laparotomy twice and finally uterine artery embolization for repeated broad ligament haematoma and responded. Massive obstetric haemorrhage remains a significant cause of maternal morbidity and mortality. The threshold for uterine artery embolization (UAE) in women with obstetric haemorrhage should be low, as it is coupled with a high clinical effectiveness rate, low complication rate and preservation of fertility. However, it requires an infrastructure, multidisciplinary approach, as well as speedy and effective interaction between various specialties.
\end{abstract}

Keywords: Hematoma, Maternal morbidity, Obstetric haemorrage, Uterine artery ligation, Uterine artery embolization maternal mortality

\section{INTRODUCTION}

In spite of advances in obstetrics and intensive care, obstetrics hemorrhage remains a main cause of maternal mortality and morbidity. Severe post partum haemorrhage $(\mathrm{PPH})$ is responsible for approximately $25 \%$ of maternal deaths. The incidence of maternal mortality due to PPH varies between countries. In developing countries, the incidence of maternal mortality is approximately 1in 1000 deliveries, whereas in developed countries the incidence is only around 1 in 10,0000 deliveries. ${ }^{1} \mathrm{PPH}$ is a common entity that complicates as many as $18 \%$ of all deliveries, defined as an estimated blood loss of more than $500 \mathrm{ml}$ by vaginal delivery and more than $1000 \mathrm{ml}$ by cesarean section. ${ }^{2}$
Various causes of obstetric haemorrhage are atonicity of uterus, retained bits of conception, placental abnormality, lacerations and coagulopathy. Depends on etiology, various management modalities are, uterotonics, surgical repair of lacerations, removal of retained product of conception, uterine packing and devascularisation. For unresponsive cases there are two standard alternatives, one is vascular ligation with success rate ranging from $40-100 \%$ and second and the last option is obstetric hysterectomy. ${ }^{3}$

Success rate of internal iliac ligation varies as there are extensive collateral present and it is technically difficult and not void of risks and in many cases, it is not possible to perform due to clinical situation. 
Selective arterial embolization (SAE) of the uterine arteries is an alternative to surgery and success rate for controlling primary and secondary $\mathrm{PPH}$ with it are reported from $85-95 \%$ and it has a low complication rate. $^{3}$

Here we report a case of repeated broad ligament haematoma due to bleeding from uterine artery managed by selective uterine artery embolization.

\section{CASE REPORT}

A 28-year-old P4L4 referred to our hospital from the district hospital with post caesarean section status with broad ligament hematomas. Indication of caesarean was previous two lower segment caesarean section (LSCS) with scar tenderness. It was an emergency LSCS. Patient reached to our hospital 11 hour after the LSCS. Two packed were kept intra-abdominally with dressing of the wound. (Abdomen was not closed). Patient received blood transfusion but numbers of the units were not mentioned in the referred slip. This was her $3^{\text {rd }}$ caesarean section. History was elicited from relatives. She conceived in lactational amenorrhoea. Her antenatal period was uneventful. She was not having any congenital or acquired coagulopathy neither she was on any anticoagulant. She was a case of chronic hypertension for which she was very irregular in treatment.

Table 1: Investigations.

\begin{tabular}{|llllllll|}
\hline Procedure & Hb & TLC & INR & Creatinine & SGOT & SGPT & $\begin{array}{l}\text { Sepsis screen } \\
\text { On admission }\end{array}$ \\
\hline & 6.3 & 26000 & 1.66 & & 60 & $\begin{array}{l}\text { Toxic granule absent band } \\
\text { form- 7\% }\end{array}$ \\
\hline Post exploratory laparotomy & 7.5 & 12600 & 1.9 & & 750 & 923 & \\
\hline Post Re-exploratory laparotomy & 8.7 & 6200 & 1.01 & & 34 & 169 & \\
\hline Pre-embolisation & 9.9 & & & & & & \\
\hline Post-embolisation & 8.1 & 11800 & 1.2 & 0.7 & 21 & 41 & TG absent band- form $1 \%$ \\
\hline On discharge & 10.2 & 4400 & 1.1 & & & &
\end{tabular}

On examination patient was unconscious, intubated, severe pallor with edema and dehydration were present. Her pulse was 170 beats/minute BP was $130 / 100 \mathrm{~mm}$ of $\mathrm{Hg}$. Respiratory rate was $25 /$ minute. SPo2 was $100 \%$. On cardiovascular examination tachycardia was present and on respiratory examination bilateral crepts were present. On per abdomen examination abdomen was soft, uterus was 22 weeks and contracted. Dressing was dry. Two packs were present in left iliac fossa. On perineal examination bleeding was not present. Patient was catheterized. Two hundred $\mathrm{ml}$ dark colour urine was present. Her investigations reports were presented in the Table 1. After arranging blood and blood component patient was shifted to operation theater for exploratory laparotomy. On laparotomy pack removed, uterus was contracted. Uterine stichline was healthy. On right side $8 \times 8 \times 8 \mathrm{~cm}$ broadligament haematoma and on left side $3 \times 3 \times 3 \mathrm{~cm}$ hematomas were present. Haematomas were drained. Bilateral uterine artery ligation was done. No retroperitoneal hematoma was present. Abdominal drain was kept in pouch of douglas. She was shifted to intensive care unit (ICU) for intensive care. Intraoperative and postoperative she received 3 units of packed cell and 4 fresh frozen plasma (FFP). Piperacillin, tazobactum and metronidazole were started. Five hours after the surgery collection was in drain was 550cc (Serousblood tinged). She was doing fairly next 2 days of laparotomy with drain output was $300 \mathrm{ml}$ (serosanginous) per day. On 21/06/18 after noon she complained pain in abdomen. On examination her pulse rate was 142/min and $\mathrm{BP}$ was 70/50, on abdominal examination tenderness, distension was present, bowel sound was absent. Drain was having $600 \mathrm{cc}$ blood in last two and half hour. Based on her clinical symptoms she was assumed to have bled intra-abdominally and shifted back to OT for relaparotomy (22/06/18). Intra-operative bilateral broad ligament haematoma were present. On left side it was $11 \times 8 \times 9 \mathrm{~cm}$ both haematomas drained. 1.5 liters haemoperitomeum was present retropertoneal haematoma was also present. Due to obscured anatomy internal iliac artery ligation was not done. Haemostasis achieved. She shifted to ICU. Intra-operative and post operative she received 3 packed cell, 4 platelet and 4 FFP. Immediate post operative period, she was intubated, pulse was122/min, BP was 140/90 mmHg but next 6 hours after the surgery, 550cc blood was collected from drain. $\mathrm{Hb}$ was $7.5 \mathrm{gm} \%$. Bed side ultrasonography reported subhepatic and POD collection. Decision for uterine artery embolization was taken. She shifted to radiology department.

\section{Procedure of embolization}

Under all aseptic precaution and under local anaesthesia bilateral common femoral artery were punctured at the level of the groin. The puncture sites were secured with $6 \mathrm{~F}$ arterial sheath. Angiography of right uterine artery was performed with $5 \mathrm{~F}$ vertebral catheter terummo, 
negotiated through left arterial sheath revealed narrowing (postligation) with no abnormal vascular blush. The left uterine catheter was selectively cannulated with $5 \mathrm{~F}$ vertebral glide catheter negotiated through right arterial sheath and revealed narrowing at left uterine artery (postligation) with abnormal vascular blush at the pelvic region. (Figure 1, 2, 3) The artery was embolized with 300micron PVA (polyvinyl alcohol) particles and immediate post procedure angiography showed complete obliteration of the vascular blush (Figure 4).

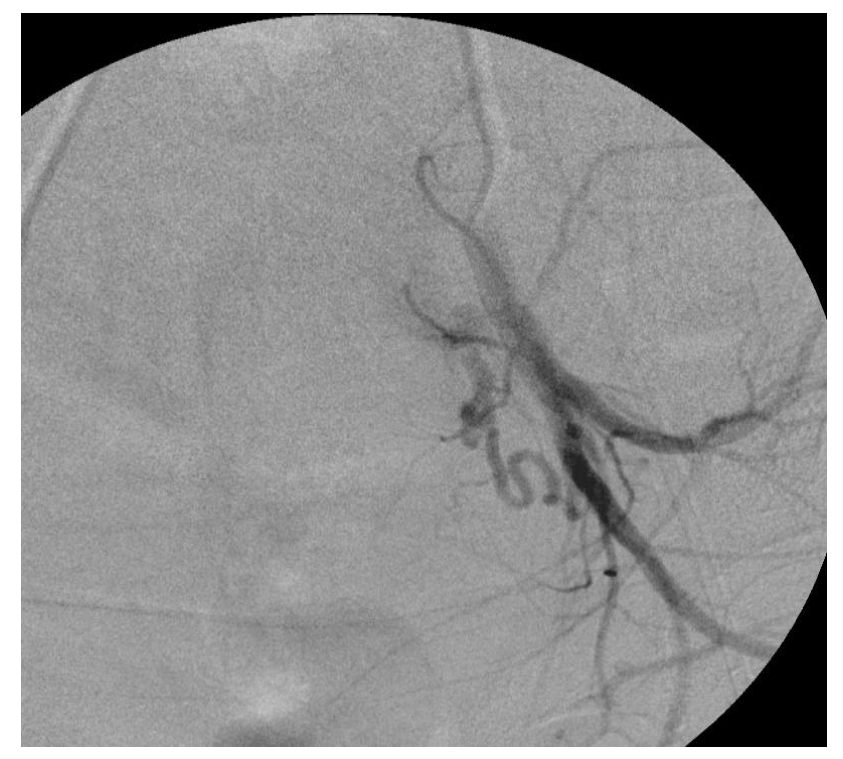

Figure 1: Selective angiography of the left uterine artery $(\mathrm{A}, \mathrm{B}, \mathrm{C})$ revealed narrowing at left uterine artery origin with abnormal vascular blush at the pelvic region.

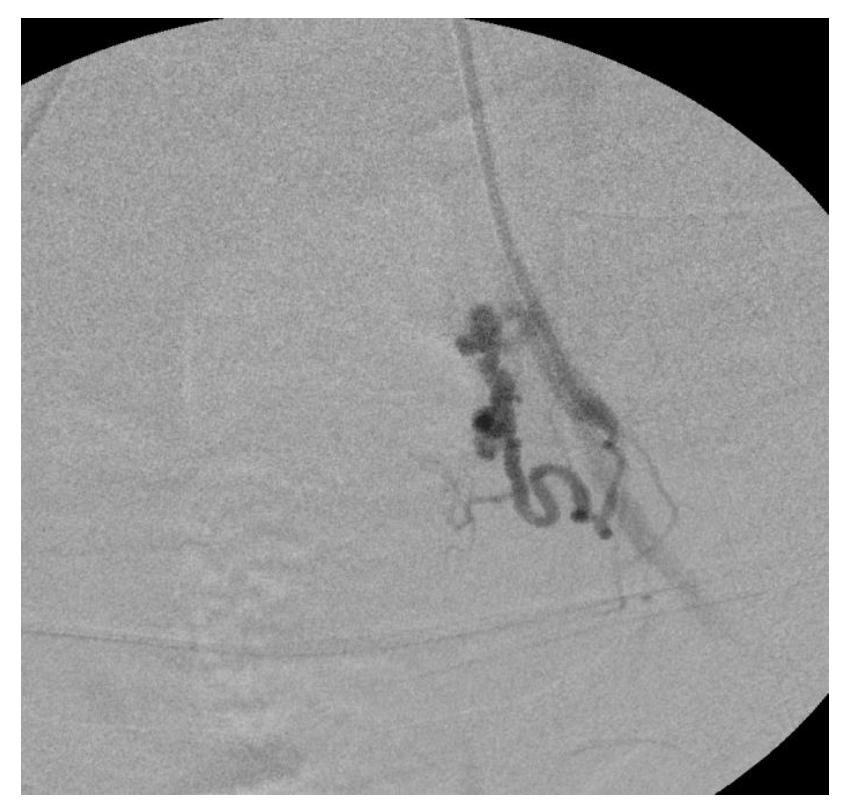

Figure 2: Selective angiography of the left uterine artery $(\mathrm{A}, \mathrm{B}, \mathrm{C})$ revealed narrowing at left uterine artery origin with abnormal vascular blush at the pelvic region.

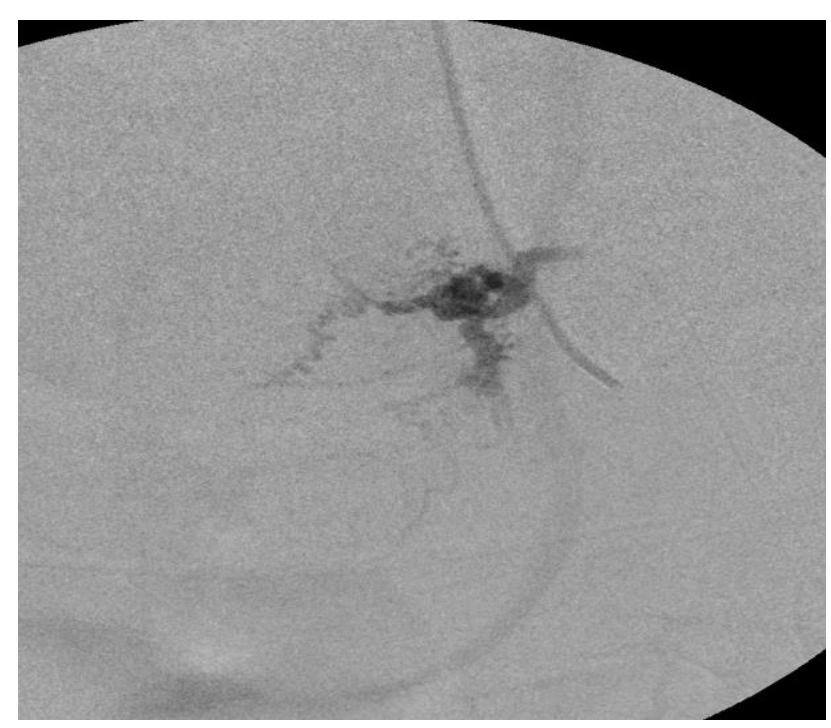

Figure 3: Selective angiography of the left uterine artery $(A, B, C)$ revealed narrowing at left uterine artery origin with abnormal vascular blush at the pelvic region.

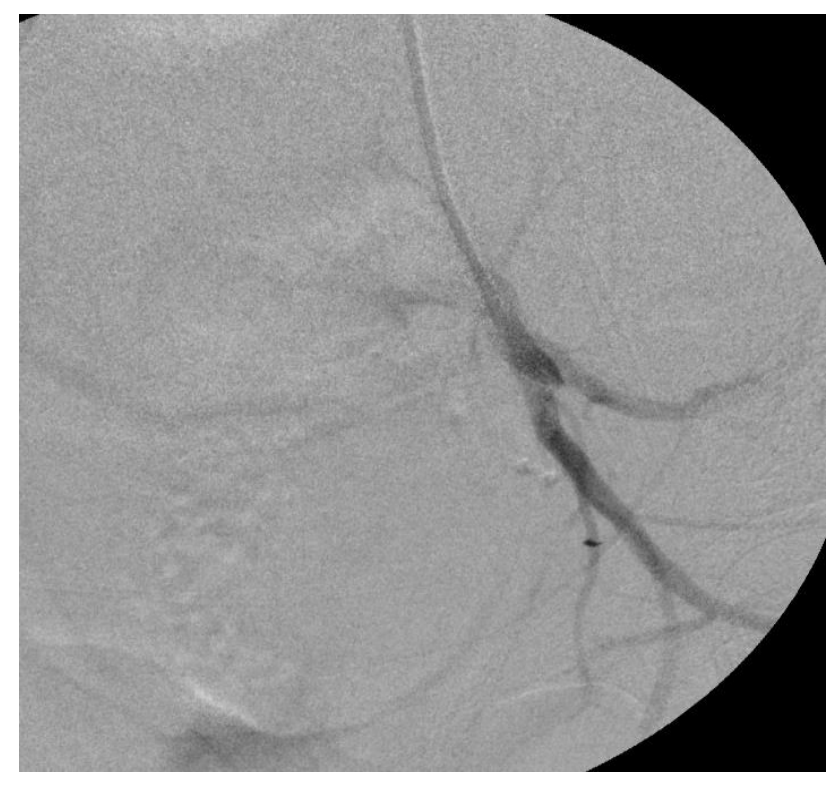

Figure 4: The artery was embolized with 300micron PVA (Polyvinyl alcohol) particles and immediate post procedure angiography (D) showed complete obliteration of the vascular blush.

Post embolization her $\mathrm{Hb}$ was $8.4 \mathrm{gm} \%$ and drain collection was $20 \mathrm{ml}$.

She did well 2 days after embolization but she had started fever. On evaluation for fever her sputum culture report revealed growth of acinobacter and klebsiela pnemoniae which were panresistant to antibiotic. Same organism found in her wound and vaginal growth. She received ciprofloxacin, miropenum also. She responded with tegecycline. Patient developed wound gaping for which resuturing done. She dischared well after removal of suture. 


\section{DISCUSSION}

When medical management fails to control the haemorrhage, one has to sort for surgical intervention. The type of intervention depends upon a number of factors, most important is the experience of the surgeon. Other factors taken into consideration are parity and desire to retain fertility potential, the amount of the hemorrhage, the condition of the patient and place of delivery.

In hemodynamically stable patient not responding to the medical treatment with uterotonics, early contemplation and execution of arterial embolisation has many advantages, in comparison to immediate surgical interventions such as internal iliac artery ligation or hysterectomy. ${ }^{3}$ It not only allows the uterus to be retained and therefore preservation of fertility potential but angiographic catheter placement under fluoroscopy permits accurate localization of the bleeding and collateral vessels, facilitating targeted embolisation to control the bleeding and prevent re bleeding which can occur via the collateral circulation. This may explain higher success rates $(>90 \%)$ of uterine artery embolization (UAE) compared with internal iliac artery ligation (40-75\%). ${ }^{3,4}$ It also avoids the risks coupled with laparotomy and major surgery and general anaesthesia. If embolisation fails, hysterectomy can still be performed as last resort if source of bleeding is uterine. However, uterine artery embolization is not safe for unstable patients with heavy bleeding who need to be transferred to a faraway radiology department for angiographic embolisation. Ideally delivery suite or operation room should be equipped with set up for angiography and a dedicated radiology team on standby. Tran catheter arterial embolization has been an established method of haemorrhage control since the 1960s, and has been used to control pelvic haemorrhage due to trauma, malignancy and radiation. ${ }^{4}$ This technique has been used successfully in the control of postpartum haemorrhage, with the first such reported use in 1979 by Brown. 5,6

In one of the studies, in cases of uterine atony, the documented success rate of UAE was $100 \% .^{7}$ However, it was reported that abnormal placentation accounts for over half of the failures of UAE. ${ }^{8}$ Reported success rates of UAE for adherent placentation indication were $71 \% .^{8}$

In another study nine out of the eleven were treated successfully with UAE. One patient needed an emergency hystetrectomy for intractable bleeding. ${ }^{9}$

In one more study with uterine artery embolization for primary postpartum haemorrhage 60 patient underwent uterine artery embolization. Bilateral UAE was performed in 49 cases. Success rate for UAE was $96 \%$. For two case, UAE complication was associated with fever $\left(38.5^{\circ} \mathrm{C}\right)$. Five patients had problem that required admission to intensive care unit. ${ }^{10}$
Ganguli S et al, reported in their study with 66 women underwent UAE for obstetric haemorrhage with overall clinical success rate was $95 \%$ (55for primary PPH and $88 \%$ for secondary $\mathrm{PPH}$ and $94 \%$ for PPH associated with cesarean section) and overall complication rate was $4.5 \%$. Mean pre and post embolization transfusion requirement were $3.1 \mathrm{U}$ and $0.4 \mathrm{U}$ of packed red cells. ${ }^{11}$

In another study, Badaway and colleagues reported success rate of $94.9 \%$ and a complication rate of $8.7 \% .^{5}$ The commonest complication is low-grade fever and rarer ones include pelvic infection, groin haematoma, iliac artery perforation, transient buttock ischaemia, transient foot ischaemia and bladder gangrene. ${ }^{5}$ Some authors recommended uterine artery embolization should be first choice in severe postpartum haemorrhage, not controlled on medical management. ${ }^{12}$ Certain practical issues should be taken into consideration. Availability of infrastructure for vascular intervention as well as availability of trained radiologist round the clock is a must. Uterine artery embolization and uterine artery ligation both have documented success rates of more than $92 \%$ with little complication rates. If both procedures are accessible, embolization should be the first choice of treatment as it avoids surgery, and uterine artery ligation can be tried afterwards if embolization is failed. After a failed uterine artery ligation, embolization may be enormously tricky or even unattainable, leaving hysterectomy as the only lasting choice. ${ }^{13}$ Although, in present case embolization performed after uterine artery ligation which can be technically difficult at times. In this case due to repeated broad ligament haematoma even hysterectomy could not be useful. Uterine artery ligation was done at the time of laparotomy. Due to presence of retroperitoneal haematoma and obscured anatomy internal iliac artery ligation was not attempted.

UAE has been reported to be an effective and safe means for managing intractable postpartum haemorrhage. Complications from embolus migration to the general blood circulation are very rare. Ischemic uterine necrosis after UAE with polyvinyl alcohol and Gelfoam particles was reported in one study and in their case a hysterectomy was finally performed because of pelvic pain and persistent menorrhagia. ${ }^{14}$

Porcu et al, reported uterus and bladder necrosis after UAE for PPH. ${ }^{15}$

Many studies reported a return of normal menses and preservation of future fertility with successful uneventful pregnancies after SAE. ${ }^{16,17}$

Despite it is very efficient in controlling severe PPH, arterial embolisation is an underused entity probable causes may be unavailability of infrastructure and or trained radiologist.

Awareness of the safety and effectiveness of this procedure is likely to increase the popularity of this 
modality of treatment. Such a service should be available in all large obstetric units. The threshold for UAE in women with PPH should be low, as it is associated with a high clinical efficacy rate and a low complication rate.

\section{CONCLUSION}

Massive obstetric haemorrhage remains a significant cause of maternal morbidity and mortality. The threshold for UAE in women with obstetric haemorrhage should be low, as it is coupled with a high clinical effectiveness rate, low complication rate and preservation of fertility. It also avoids morbidity associated with surgery. However, it requires an infrastructure, multidisciplinary approach, as well as speedy and effective interaction between various specialties.

Funding: No funding sources Conflict of interest: None declared

Ethical approval: Not required

\section{REFERENCES}

1. Papp Z. Massive obstetric hemorrhage. J Perinat Med. 2003;31:408-14.

2. Devine PC. Obstetric hemorrhage. Semin Perinatol. 2009;33:76-81.

3. Chandraharan E, Arulkumaran S. Management algorithm for atonic postpartum haemorrhage. JPOG. 2005;31:106-12.

4. Ring EJ, Athanasoulis C, Waltman AC, Margolies $\mathrm{MN}$, Baum S. Arteriographic management of hemorrhage following pelvic fractures. Radiol. 1973;109:65-70.

5. Badaway SZA, Etman A, Singh M, Murphy K, Mayelli T, Philadelphia M. Uterine artery embolization: the role in obstetrics and gynecology. J Clin Imag. 2001;25:288-95.

6. Heaston DK, Mineau DE, Brown BJ, Miller FJ. Transcatheter arterial embolization for control of persistent massive puerperal hemorrhage after bilateral surgical hypogastric artery ligation. Am J Roentgenol. 1979;133:152-4.

7. Pelage JP, Le Dref O, Jacob D, Soyer P, Herbreteau $\mathrm{D}$, Rymer R. Selective arterial embolisation of the uterine arteries in the management of intractable post-partum hemorrhage. Acta Obstet Gynecol Scand. 1999;78:698-703.
8. Descargues G, Douvrin F, Degre S, Lemoine JP, Marpeau L, Clavier E. Abnormal placentation and selective embolisation of the uterine arteries. EJOG. 2001;99:47-52.

9. Maassen M, Lambers M, Tutein Nolthenius RP, Vander Valk PHM, Elgersma OE. Complication and failure of uterine artery embolization for intractable post partum haemorrhage. BJOG. 2009;116:55-61.

10. Kim TH, Lee HH, Kim JM, Ryu Al, Chung S, lee WS. Uterine artery embolization for primary post partum haemorrhage. Iran J Reprod Med. 2011;11(6):511-8.

11. Ganguli S, Stecker MS, Pyne D, Bahum RA, fan $\mathrm{CM}$. uterine artery embolization in the treatment of post partum uterine hemorrhage. J Vasc Interv Radiol. 2011;22:169-76.

12. Pelage JP, Soyer P, Repiquet D. Secondary postpartum hemorrhage: treatment with selective arterial embolization. Radiol. 1999;212:385-9.

13. Soncini E, Pelicelli A, Larini P, Marcato C, Monaco $\mathrm{D}$, Grignaffini A. Uterine artery embolisation in the treatment and prevention of postpartum hemorrhage. Int J Gynaecol Obstet. 2007;96:181-5.

14. Cottier JP, Fignon A, Tranquart F, Herbreteau D. Uterine necrosis after arterial embolisation for postpartum hemorrhage. Obstet Gynecol. 2002;100:1074-7.

15. Porcu G, Roger V, Jacquier A, Mazouni C, RojatHabib M, Girard G, et al. Uterus and bladder necrosis after uterine artery embolisation for postpartum haemorrhage. BJOG. 2005;112:122-3.

16. Salomon LJ, deTayrac R, Castaigne-Meary V, Audibert F, Musset D, et al. Fertility and pregnancy outcome following pelvic arterial embolization for severe post-partum haemorrhage. A cohort study. Hum Reprod. 2003;18:849-52.

17. Descargues G, Mauger Tinlot F, Douvrin F, Clavier E, Lemoine JP. Menses, fertility and pregnancy after arterial embolization for the control of postpartum haemorrhage. Hum Reprod. 2004;19:339-43.

Cite this article as: Panda S, Sharma N, Phukan P. Repeated broad ligament hematomas managed by uterine artery embolization: time to execute. Int J Reprod Contracept Obstet Gynecol 2019;8:3417-21. 